\title{
Constitutive activation of casein kinase 2 in glioblastomas: Absence of class restriction and broad therapeutic potential
}

\author{
NADEGE DUBOIS $^{1 *}$, MARIE WILLEMS ${ }^{1 *}$, MINH-TUAN NGUYEN-KHAC ${ }^{1}$, JEROME KROONEN $^{1,2}$, \\ NICOLAS GOFFART ${ }^{1,2}$, MANUEL DEPREZ ${ }^{3}$, VINCENT BOURS ${ }^{1}$ and PIERRE A. ROBE ${ }^{1,2}$ \\ ${ }^{1}$ Department of Human Genetics and GIGA Research Center, University of Liège, B-4000 Liège, \\ Belgium; ${ }^{2}$ Brain Center Rudolf Magnus, Department of Neurology and Neurosurgery, \\ University Medical Center of Utrecht, Utrecht 3584 CX Utrecht, The Netherlands; \\ ${ }^{3}$ Department of Neuropathology, CHU Liège, University of Liège, B-4000 Liège, Belgium
}

Received February 11, 2016; Accepted March 18, 2016

DOI: $10.3892 /$ ijo.2016.3490

\begin{abstract}
Casein kinase II contributes to the growth and survival of malignant gliomas and attracts increasing attention as a therapeutic target in these tumors. Several reports have suggested that this strategy might be most relevant for specific subgroups of patients, namely Verhaak's classical and TP53 wild-type tumors. Using kinase assays and microarray genetic profiling in a series of 27 proprietary fresh frozen surgical glioma samples, we showed that constitutive CK2 kinase activation is not restricted to tumors that present increased copy numbers or mRNA expression of its catalytic or regulatory subunits, and can result from a functional activation by various cytokines from the glioma microenvironment. Using corresponding primary tumor and human astrocyte cell cultures as well as glioma cell lines, we confirmed that CK2 inhibition is selectively toxic to malignant glial tumors, without any restriction to tumor class or to TP53 status. We finally showed that while the contribution of $\mathrm{CK} 2$ to the constitutive $\mathrm{NF}-\kappa \mathrm{B}$ hyperactivation in malignant gliomas is at best moderate, a delayed activation of $\mathrm{NF}-\kappa \mathrm{B}$ may associate with the therapeutic resistance of glioma cells to $\mathrm{CK} 2$ inhibition.
\end{abstract}

\section{Introduction}

Glioblastomas (GBMs) are the most aggressive and prevalent type of primary brain tumors and present a dismal prognosis with a median survival of less than two years (1).

Correspondence to: Dr Pierre A. Robe, Department of Neurology and Neurosurgery, Rudolf Magnus Brain Institute, University Medical Center of Utrecht, 100 Heidelberglaan, G03.126, 3584 CX Utrecht, The Netherlands

E-mail: p.robe@umcutrecht.nl

${ }^{*}$ Contributed equally

Key words: glioblastoma, casein kinase 2, targeted therapy, constitutive activation, $\mathrm{NF}-\kappa \mathrm{B}$, classification of Verhaak
Casein kinase 2 is a ubiquitous serine/threonine tetrameric kinase that consists of two catalytic subunits $\left(\alpha\right.$ and $\left.\alpha^{\prime}\right)$ and two $\beta$ regulatory subunits. CK2 is frequently overexpressed or overactive in aggressive forms of solid and hematological malignancies $(2,3)$, and contributes to the dysregulation of cell growth, invasion, survival and senescence via the $\beta$-catenin, JAK/STAT, mTOR, and NF- $\kappa$ B pathways (4-9). As a result, CK2 inhibitors have recently entered preliminary clinical trials for advanced solid and hematological tumors (source: ClinicalTrial.gov, accessed in December 2015).

In GBMs, CSNK2A1, the gene encoding the $\alpha$ catalytic subunit of the kinase, is amplified in one third of the tumors, and especially in those that belong to the Verhaak's 'classical' gene expression phenotype (10). CK2 has been reported to regulate tumor-initiating cell growth, tumor cell survival, DNA repair following ionizing radiation, and apoptosis in these tumors $(4,5,7,8,11-13)$. As a result, CK2 inhibition with drug inhibitors or siRNA technology was shown to alter the growth, survival and migration of glioma cell lines and slow down the growth of GBMs xenografts in immunodeficient mice $(9,14)$.

Prior to translating these findings to the bedside however, it remains unclear whether CK2 hyperactivity is restricted to classical GBMs presenting a CSNK2A1 amplification or not and/or whether all malignant glial tumors are evenly likely to benefit from CK2 inhibitory strategies.

This report provides evidence that CK2 kinase hyperactivity occurs in vivo in all classes of GBMs as well as in glial tumors of lower grades and histology, and can be a target independently of Verhaak's classes and its TP53 status. However, additional factors, such as the NF- $\mathrm{B}$ response to $\mathrm{CK} 2$ inhibition, may modulate the efficacy of this therapeutic strategy.

\section{Materials and methods}

Genetic analyses. The GISTIC 2.0 copy number data and Agilent-based mRNA expression data of 538 glioblastoma samples of the TCGA repository were obtained from the UCSC Cancer Genomics Browser (accessed in September 2015). Threshold copy number (CN) values were used to perform the correlations with mRNA expression data using Pearson 
correlation tests. $\mathrm{CN}$ analysis and mRNA expression analyses were also run on 27 glial tumor samples of various histology from the University Medical Center of Utrecht (UMCU), using Affymetrix SNP6.0 $(n=25), 250 \mathrm{~K}$ arrays $(n=2)$ and the circular binary segmentation (CBS) method after correction for batch effect. These fresh frozen surgical samples were obtained at the UMCU following written informed consent of the patients, following approval of their collection by the relevant ethics committee, and maintained in liquid nitrogen until use. Additional three fresh surgical samples of non-tumoral epileptogenic brain (temporal lobe epilepsies) and three fresh frozen brain autopsy specimens sampled within an hour postmortem from patients deceased from non-neurological causes were obtained from the neuropathology biobank of the University of Liège, in agreement with the local Ethics Committee. The DNA and mRNA of these tumors were obtained by Nucleospin ${ }^{\circledR}$ TriPrep kit (Macherey-Nagel, Belgium) and the QIASymphony RNA kit (Qiagen, The Netherlands). The mRNA expression patterns were analyzed using Affymetrix U133 Plus 2.0 arrays, following RNA normalization, correction for batch effect. The molecular subclassification (proneural, neural, classical, mesenchymal) was predicted by hierarchical clustering (10). The Partek ${ }^{\circledR}$ suite and R-software were used to generate these analyses.

Tissue microarrays and immunohistochemistry. Formalinfixed, paraffin-embedded tumor tissues of a consecutive series of GBMs operated at the University Hospital Center of Liège and from the 27 tumor UMCU samples described above were processed and included in tissue microarrays (TMAs). Details on TMA construction and immunohistochemistry have been described previously (15). A primary antibody to CK $2 \alpha$ (Santa Cruz) was used for the immunostaining, as described previously (16) and revealed using secondary antibodies and diaminobenzidine (DAB).

Cell cultures, reagents and siRNA. Human U87 malignant glioma cells were obtained from the ATCC and their CGH and TP53 genetic profiles were confirmed using Affymetrix $250 \mathrm{~K}$ arrays and TP53 sequencing. Human primary GBM cells were derived from fresh samples of human GBMs, as published previously (16) after Ethics Committee approval and informed patient consent. Cells were grown at $37^{\circ} \mathrm{C}$ in $5 \% \mathrm{CO}_{2}$ in DMEM (Life Technologies ${ }^{\mathrm{TM}}$ ) supplemented with $10 \% \mathrm{FBS}\left(\mathrm{Gibco}^{\circledR}\right)$ and $1 \%$ of $5 \mathrm{mg} / \mathrm{ml}$ penicillin-streptomycin solution (Gibco).

Apigenin (Sigma-Aldrich) and Cx4945 (Cylene Pharmaceuticals and ApexBio) were dissolved in dimethylsulfoxide (DMSO) and used at final concentration of 40 and $20 \mu \mathrm{M}$, respectively. Control cells were treated with a similar final concentration of DMSO as the drug-treated cells. Calpain inhibitor I (a cell-permeable peptide inhibitor: N-Acetyl-LeuLeu-Norleu-al, N-Acetyl-L-leucyl-L-leucyl-L-norleucinal) was obtained from Sigma-Aldrich and used at a concentration of $20 \mu \mathrm{M}$.

For siRNA experiments, subconfluent cultured cells were transfected with $50 \mathrm{nmol} / \mathrm{ml}$ of ON-TARGETplus non-targeting pool (siRNA CTRL) or SMARTpool human CSNK2A1 siRNA from Dharmacon (Fisher Scientific) using oligofectamine (Invitrogen) according to the manufacturer's instructions. Cells were harvested and assayed $48 \mathrm{~h}$ after transfection. CK2 depletion was controlled using western blot analysis of the expression of CK2 2 .

CK2 kinase assays. Cells were lysed using RIPA buffer extraction kit (Santa Cruz Biotechnology) and $300 \mu \mathrm{g}$ of proteins were taken for immunoprecipitation. After a precleared step, supernatants were incubated with an anti-CK2 antibody (clone 1AD9, Millipore) under rotary agitation for $4 \mathrm{~h}$ at $4^{\circ} \mathrm{C}$. GammaBind $\mathrm{G}$ Sepharose beads $(25 \mu \mathrm{l} /$ sample, GE Healthcare) were then added to the samples and incubated on a rotating system overnight at $4^{\circ} \mathrm{C}$. After three washes, immunoprecipitated proteins were processed with the CK2 assay kit (Upstate, Millipore) according to the manufacturer's instructions.

$N F-\kappa B$ transcription assay. Cells were seeded at a density of $2 \times 10^{6}$ cells in $35-\mathrm{mm}$ wells and co-transfected using TransIT-2020 transfection reagent (Mirus) with: i) a luciferasecoupled reporter gene for $\mathrm{NF}-\kappa \mathrm{B}$ and ii) a Renilla luciferase reporter driven by a constitutive promoter. Twenty-four hours after this step, cells were treated for $6 \mathrm{~h}$ (Apigenin, Cx4945) or $3 \mathrm{~h}$ (calpain inhibitors) and lysed for analysis. For siRNA experiments, cells were first transfected for $48 \mathrm{~h}$ with the CTRL or CK $2 \alpha$ siRNA using the Dharmafect (Dharmacon) system, according to the manufacturer's instructions. Cells were then co-transfected with the Luciferase and Renilla plasmids as described supra. Cells were then lysed and luciferase activities were measured according to the manufacturer's instructions for the Dual Luciferase Assay System (Promega) using a Victor luminometer (Perkin-Elmer). The relative NF- $\kappa$ B luciferase activity was normalized to that of the Renilla.

Western blot analysis. Polyacrylamide precast gels (10\%) (Mini Protean TGX, Bio-Rad) were run for $30 \mathrm{~min}$ at $200 \mathrm{~V}$ with protein extracts $(20 \mu \mathrm{g} /$ well) obtained from siRNA CTRL or siRNA CK2-treated cells. Protein extracts were obtained using conventional RIPA buffer and phosphatase inhibitors. After transfer to a PVDF membrane (Roche) for $2 \mathrm{~h}$ at $300 \mathrm{~mA}$ and blocking with Tris-buffered saline containing $0.2 \%$ Tween plus $5 \%$ dry milk powder, membranes were incubated overnight at $4^{\circ} \mathrm{C}$ in the presence of primary antibody directed against CK2 $\alpha$ (Rabbit Polyclonal, 1/500, Santa Cruz Biotechologies). A horseradish peroxidase-coupled secondary antibody was then incubated and peroxidase activity was evidenced with the Super Signal West Pico Chemiluminescent substrate (Thermo Fisher Scientific) and the ImageQuant LAS 4000 Mini Biomolecular Imager (GE Healthcare).

Cell survival assays. Cell survival in response to siRNA, apigenin and Cx4945 treatments was assayed on subconfluent cells in 96-well plates using MTS tests (One Solution Cell Proliferation assay, Promega) as recommended by the manufacturer.

Statistical analysis. Statistical analyses were performed using the Prism 5.0c (Graphpad Inc., La Jolla, CA, USA) and the SPSS 23 (IBM) sofware. One-way ANOVA, Student's t-tests and $\chi^{2}$ tests were performed as appropriate and as described in the results section. Results are shown as means \pm SD. 

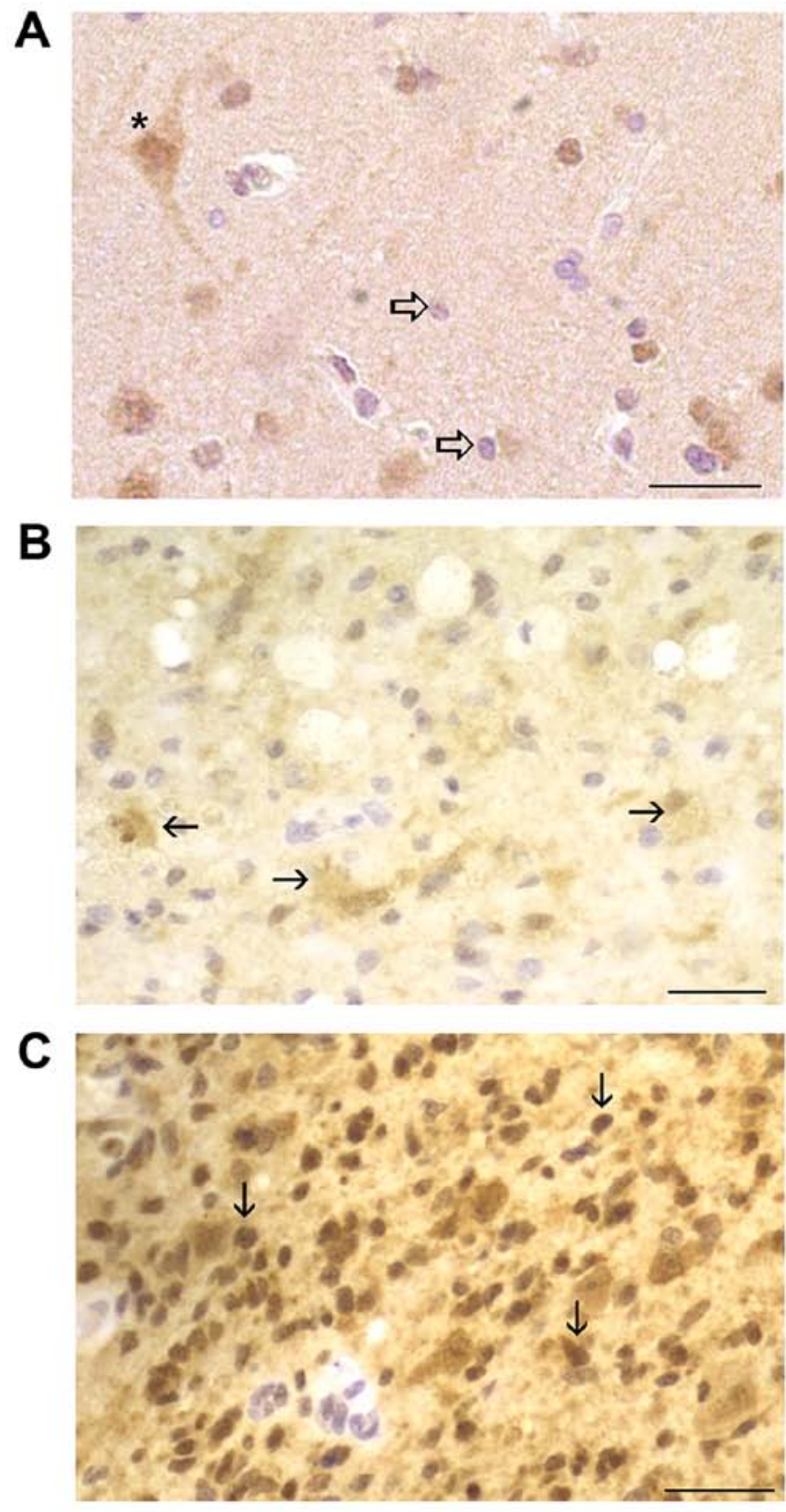

D

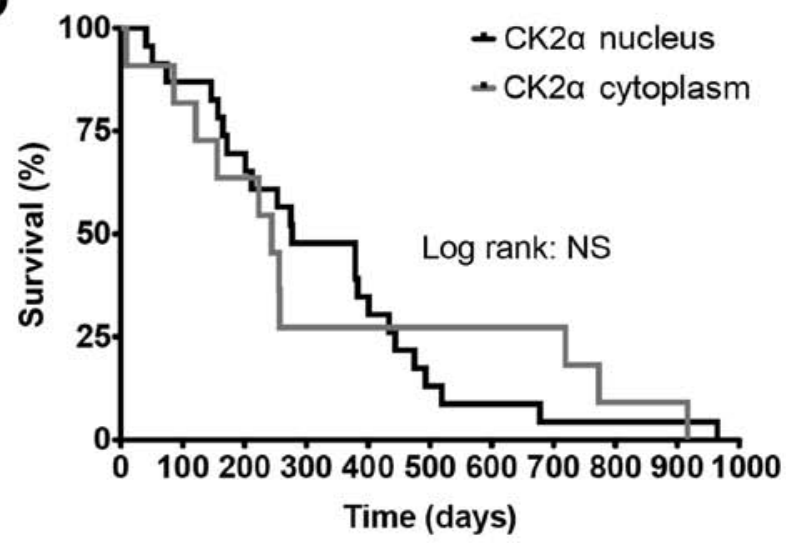

Figure 1. Expression of CK2 $\alpha$ in glioblastomas and in normal human brain samples. Immunocytochemical demonstration of the expression of CK2 $\alpha$ in (A) a specimen of non-tumoral brain tissue and (B and C) in an independent serie of 34 GBMs. Cells from all tumors appeared to abundantly express CK2 $\alpha$ either in the cytoplasm (horizontal arrows) and/or in the nucleus (vertical arrows), in contrast with normal glial cells (A; thick arrow). Note that neurons $\left(\mathrm{A},{ }^{*}\right)$ also express CK2 $\alpha$. (D) The subcellular localization of CK2 alpha in GBMs did not correlate with patient survival, as shown with Kaplan-Meier estimates for this series of patients (bars, $50 \mu \mathrm{M}$ ).

\section{Results}

CK2 is widely overexpressed in glioblastomas. CK2 $\alpha$ immunostaining was performed on FFPE sections of a consecutive series of 34 GBMs and on a normal brain tissue obtained from an epilepsy surgery. In the non-tumoral brain specimen, the CK2 $\alpha$ immunostaining was limited to neuronal cells, while glial cells did not show any significant staining (Fig. 1A). All glial tumors stained positive for this kinase. While in some tumors this staining was limited to the cell cytoplasm, it also involved the nucleus in other tumors (Fig. 1B and C), but there was no difference in survival between tumors with these two staining patterns (log-rank test, $P>0.05$, Fig. 1D).

CK2 hyperactivity is not class restricted and does not correlate with CSNK2 gene copy number alterations. The overexpression of CK2 $\alpha$ in all samples of a consecutive series of GBMs is surprising since CSNK2A1 amplification was reported to underlie the overexpression of CK2 $\alpha$ in GBMs and to prevail by large in GBMs of the classical subtype according to Verhaak et al (10). We therefore assessed the CK2 kinase activity in a series of 27 fresh frozen glial tumor samples, 3 fresh frozen epilepsy brain surgery samples and 3 otherwise healthy postmortem brain samples. While the CK2 $\alpha$ kinase activity was very similar in all six samples from non-tumoral brains, it was significantly higher in most samples from glial brain tumors, irrespectively of tumor grade (WHO grade 2, 3 or 4), histology (oligodendrogliomas, astrocytomas, glioblastomas) and gene expression subtypes of GBMs (Fig. 2). Likewise, CK2 hyperactivity did neither correlate with the copy number of any of the components of the kinase complex (CSNK2A1, CSNK2A2, CSNK2B) in these tumors, nor with the level of expression of their mRNA (Fig. 2).

The activity of CK2 $\alpha$ did not correlate with the copy number of known regulators of its activity, such as the TGF- $\beta$ receptors 1 and $2, \mathrm{PKC}-\zeta, \alpha$ and $\beta$, or p38 MAPK (data not shown). On the contrary, both TGF- $\beta 1$ and TNF- $\alpha$, which are overexpressed in GBMs, did increase the activity of CK2 $\alpha$ in malignant glioma cultures (Fig. 3), suggesting that the constitutive hyperactivity in malignant gliomas is not solely due to defined genetic changes, contrary to what was previously suggested (9).

The cytotoxic effect of CK2 inhibition is neither class nor TP53-WT restricted in glioblastomas. Malignant glioma cell lines and primary tumor cultures from a series of GBMs of different Verhaak's classes and TP53 status as well as normal human astrocytes were treated with well established CK2 inhibitors [apigenin $(40 \mu \mathrm{M}), \mathrm{Cx} 4945(20 \mu \mathrm{M})$ ] or siRNA targeting CK2 $\alpha$. CK2 inhibition did not alter the survival of normal human astrocytes in culture. All GBM cultures showed a significantly reduced viability following these treatments, albeit this toxicity varied between cultures, as measured by MTS tests (Fig. 4). However, the sensitivity to CK2 $\alpha$ inhibition correlated neither with the copy number of CK2 subunits in the tumors, nor with their TP53 status.

Variability of the $N F-\kappa B$ response to CK2 inhibition in malignant gliomas. U87 and LN18 cells significantly differ with respect to their sensitivity to the toxic effect of CK2 inhibition 


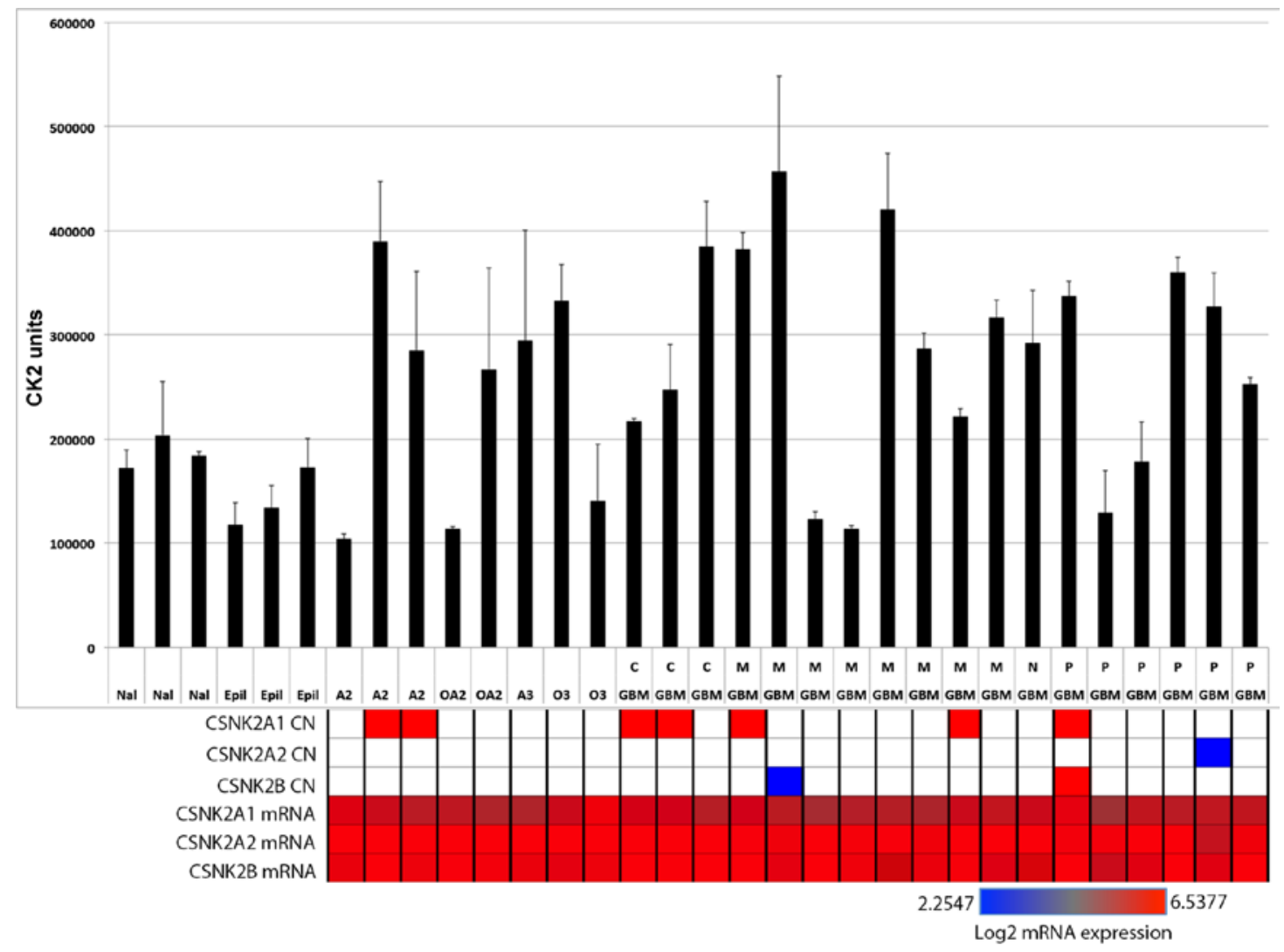

Figure 2. Kinase activity of CK2 $\alpha$ in glioma and non-tumoral human brain samples. Kinase assays performed on fresh-frozen samples of gliomas of various histology, phenotypes and histological grade show that CK2 is widely active in gliomas, irrespectively of their histology or phenotype, as compared to nontumoral human brain tissue. O, oligodendroglioma; A, astrocytoma; OA, oligoastrocytoma; GBM, glioblastoma; Epil, non-tumoral brain sample obtained from an epilepsy surgery patient; Nal, fresh frozen early postmorten brain tissue sample; 2, 3, World Health Organization (WHO) tumor grade; classes of Verhaak (GBM only): C, classical; P, proneural; N, neural; M, mesenchymal. Gene copy number and mRNA expression as measured using Affymetrix microarrays are shown for all tumor samples (SNP 6.0 and U133 Plus 2.0 respectively, see text for details).
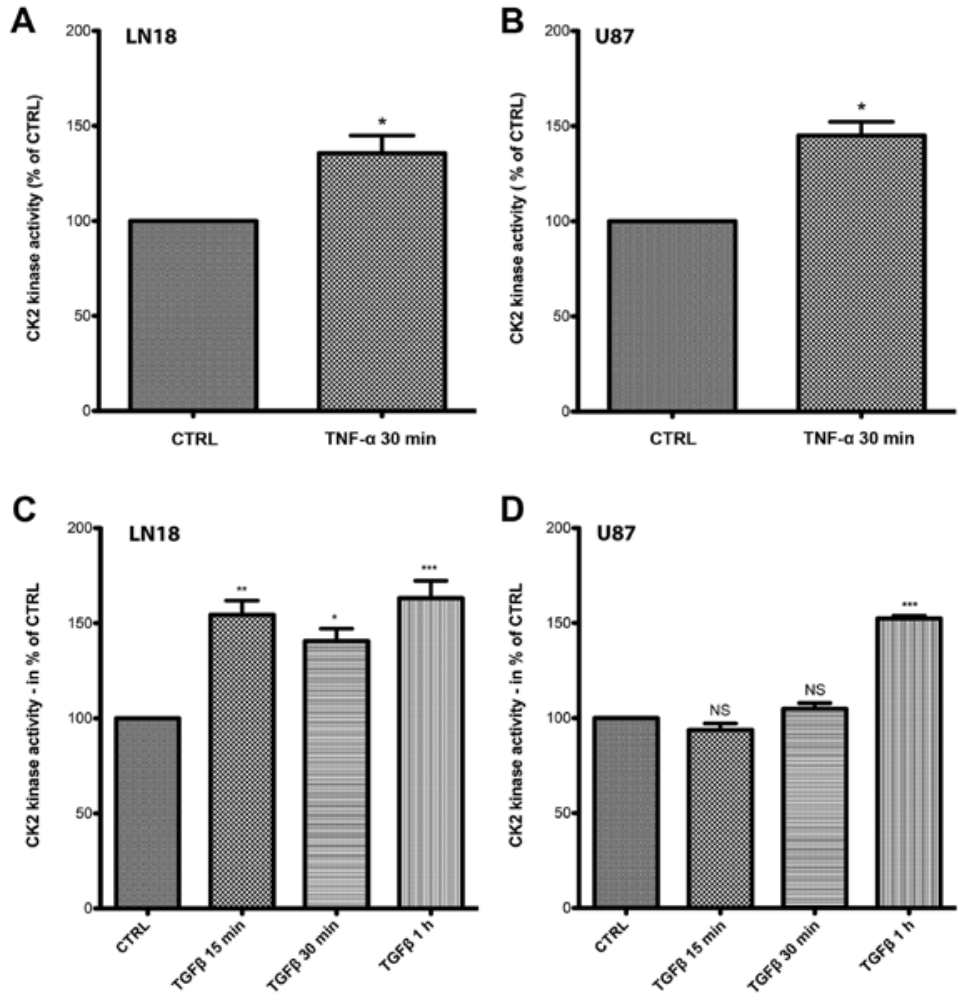

Figure 3. TGF $\beta$ and TNF $\alpha$ modulate CK2 activity in malignant glioma cell lines. CK2 $\alpha$ kinase activity was measured in LN18 and U87 cells following stimulation with TGF 31 (A, LN18; B, U87) or TNF $\alpha$ (C, LN18; B, U87). Statistics: (A and B) Student's t-test; (C and D) ANOVA with Tukey's multiple comparisons tests $\left({ }^{*} \mathrm{P}<0.05,{ }^{* *} \mathrm{P}<0.01{ }^{* * *} \mathrm{P}<0.001\right)$. 
A
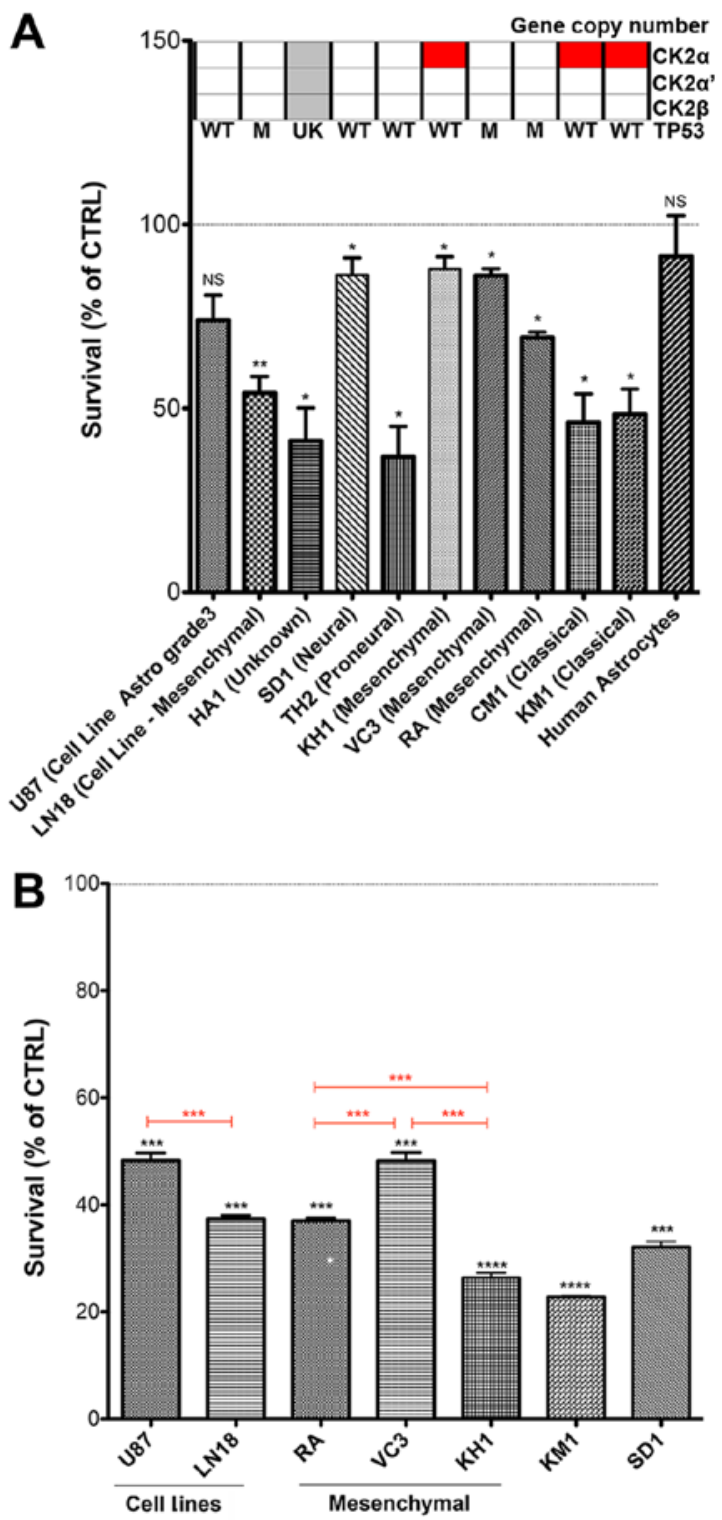

C

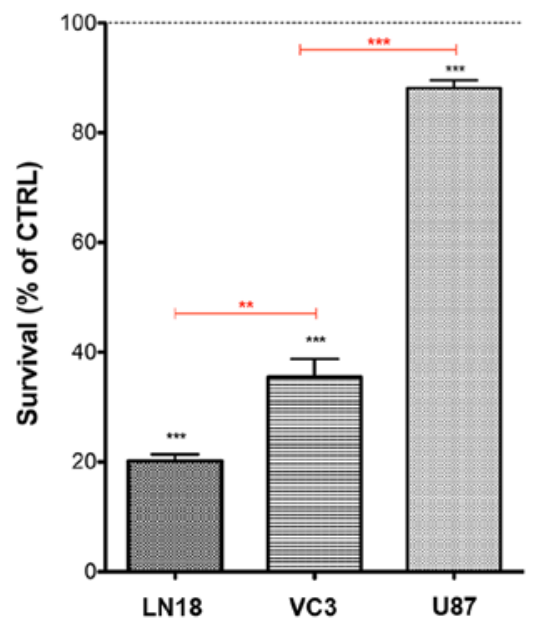

Figure 4. Toxicity of CK2 $\alpha$ inhibition on malignant glioma cell lines, primary cultures and normal human astrocytes. Cells were treated with the CK2 drug inhibitors apigenin (A), Cx4945 (B) or CK2 siRNA (C), and their survival was assessed after $48 \mathrm{~h}$. The classification of the different cell cultures according to Verhaak and their respective copy numbers of the three CK2 subunits are also provided (A). Statistics: black symbols, one sample t-tests (control, untreated cells); red, ANOVA with Tukey's multiple comparisons tests ( $\left(\mathrm{P}<0.05,{ }^{* *} \mathrm{P}<0.01\right.$

$\left.{ }^{* * * *} \mathrm{P}<0.001{ }^{* * * *} \mathrm{P}<0.0001\right)$. N, normal; WT, wild-type; UK, unknown. Color code: red, $\mathrm{CN}$ amplification; white, normal $\mathrm{CN}$; grey, unknown.
(Fig. 4). As CK2 has been reported to control both the calpaindependent degradation of I $\mathrm{B} \alpha$ and the activation of IKK $\beta$ $(6,17)$, and since NF- $\kappa B$ is a major determinant of glioma cell survival $(16,18,19)$, we assessed the control of NF- $\kappa B$ by CK2 $\alpha$ in our cultures.

The treatment of both U87 and LN18 cells with Cx4945 $(20 \mathrm{mM})$ or apigenin $(40 \mathrm{mM})$ for $3 \mathrm{~h}$ significantly reduced their NF- $\mathrm{BB}$ activity (Fig. 5A). Calpain inhibition, which was significantly toxic to both U87 and LN18 (Fig. 5B), did not, however, alter the baseline NF- $\mathrm{\kappa B}$ activity of these cells within this time frame (Fig. 5C), meaning that this alternative route of NF- $\kappa \mathrm{B}$ activation plays only a limited role in these cells. CK2 inhibition with apigenin on the other hand resulted in a significant but transient inhibition of IKK $\beta$ in both LN18 and U87 cells, with a recovery to baseline within $3 \mathrm{~h}$ of treatment (Fig. 6A). After a more durable inhibition ( 48 h) of CK2 $\alpha$ using siRNA (Fig. 6B), the NF- $\mathrm{BB}$ activity in LN18 remained unchanged, but was very significantly enhanced in U87 cells (Fig. 6C).

\section{Discussion}

CK $2 \alpha$ exerts a pro-survival role for malignant glioma cells $(4,9)$ and glioma tumor-initating cells (8). As a result, clinical trials are being designed to treat these tumors with small CK2 drug inhibitors (9). In order for such trials to be adequately designed however, one must define whether all GBMs are likely to benefit from this treatment, or if predictive markers of efficacy can be defined. CK2 mRNA overexpression was for instance reported to prevail in (classical) GBMs carrying an amplification of CSNK2A1 (9). That report, based on TCGA data, did however not assess the correlation between CSNK2A1 amplification/mRNA expression and the actual kinase activity of CK2 in tumors. Moreover, our analysis of CSNK2A1 copy number alterations (CNAs) and mRNA expression in the TCGA database showed that all classes present CSNK2A1 $\mathrm{CN}$ gains and that both classical and proneural GBM express similar quantities of CSNK2A1 mRNA (Fig. 7). Furthermore, in our proprietary series of gliomas, we observed that the CK2 kinase activity is high in gliomas independently from GBM class, glioma histology or grade, and that this kinase activity does not correlate with CNAs of any of the genes that code for the CK2 subunits or for classical regulators of CK2 activity, namely TGF- $\beta$ receptors 1 and $2, \mathrm{PKC}-\zeta, \alpha$ and $\beta$, or p38 MAPK. Of note however, we previously observed that the activity of CK2 $\alpha$ is modulated in malignant gliomas by the expression of connexin 30, a tumor suppressor encoded by GJB6 (20). We likewise observed here that TNF- $\alpha$, as well as TGF- $\beta 1$, which are secreted in the microenvironment of gliomas (21-23), can induce the activity of CK2 $\alpha$ and might thus contribute to its hyperactivity in gliomas. These results corroborate a previous report that the activation of NF- $\mathrm{KB}$ in response to TNF- $\alpha$ stimulation depends on CK2 (9).

The toxic effect of CK2 inhibition however varied in efficacy between our malignant glioma cell lines and primary cultures, irrespectively of their class, while it did not have any significant effect on normal human astrocytes in culture. This variable sensitivity was observed for both the pharmacological and siRNA-mediated inhibition of CK2, meaning that it is not likely dependent on drug-efflux proteins. Additionally, the 

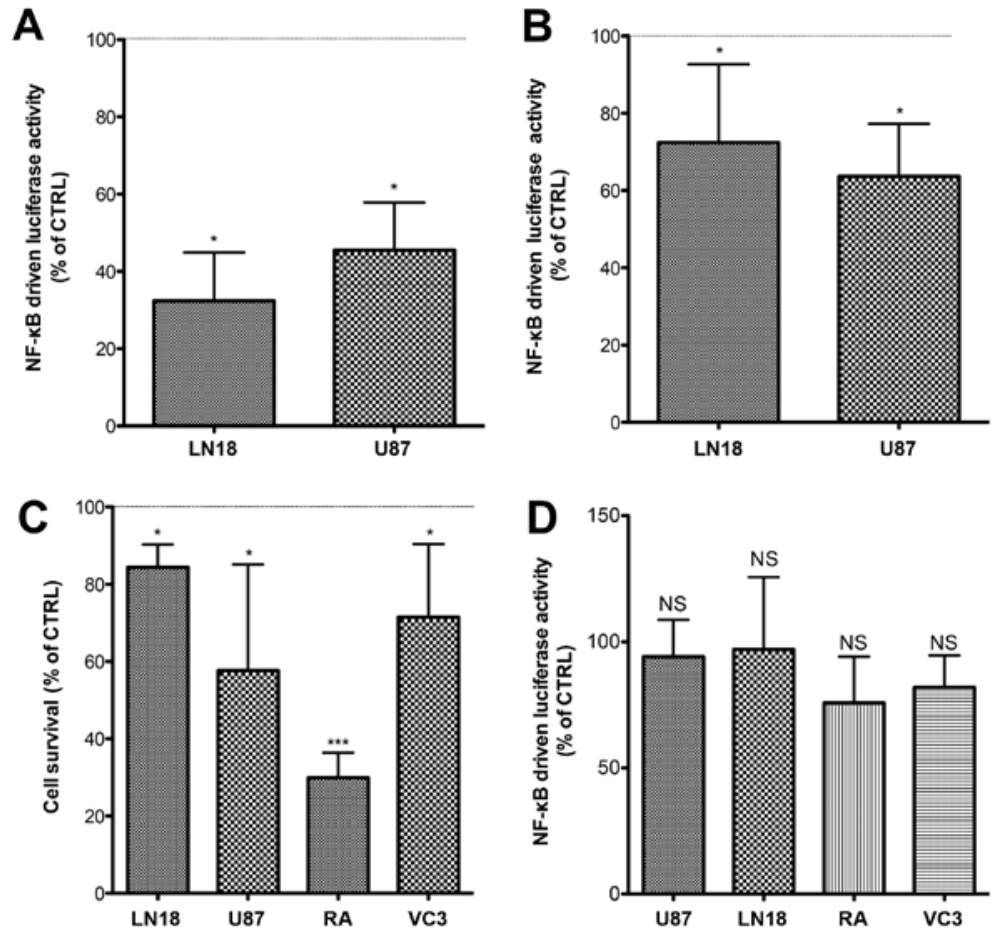

Figure 5. CK2, calpain and early NF- $\mathrm{kB}$ activity in malignant glioma cells. (A) Apigenin and (B) Cx4945 inhibited NF- $\mathrm{BB}$ reporter gene activity in LN18 and U87 cells ( $\mathrm{t}=1 \mathrm{~h}$ and $3 \mathrm{~h}$ respectively). (C) Calpain inhibition was toxic to malignant gliomas ( $\mathrm{t}=48 \mathrm{~h}$ ) but (D) failed to inhibit NF- $\mathrm{kB}$ activity in these cells $(\mathrm{t}=3 \mathrm{~h})\left(\mathrm{P}<0.05,{ }^{* *} \mathrm{P}<0.01,{ }^{* * *} \mathrm{P}<0.001\right)$.
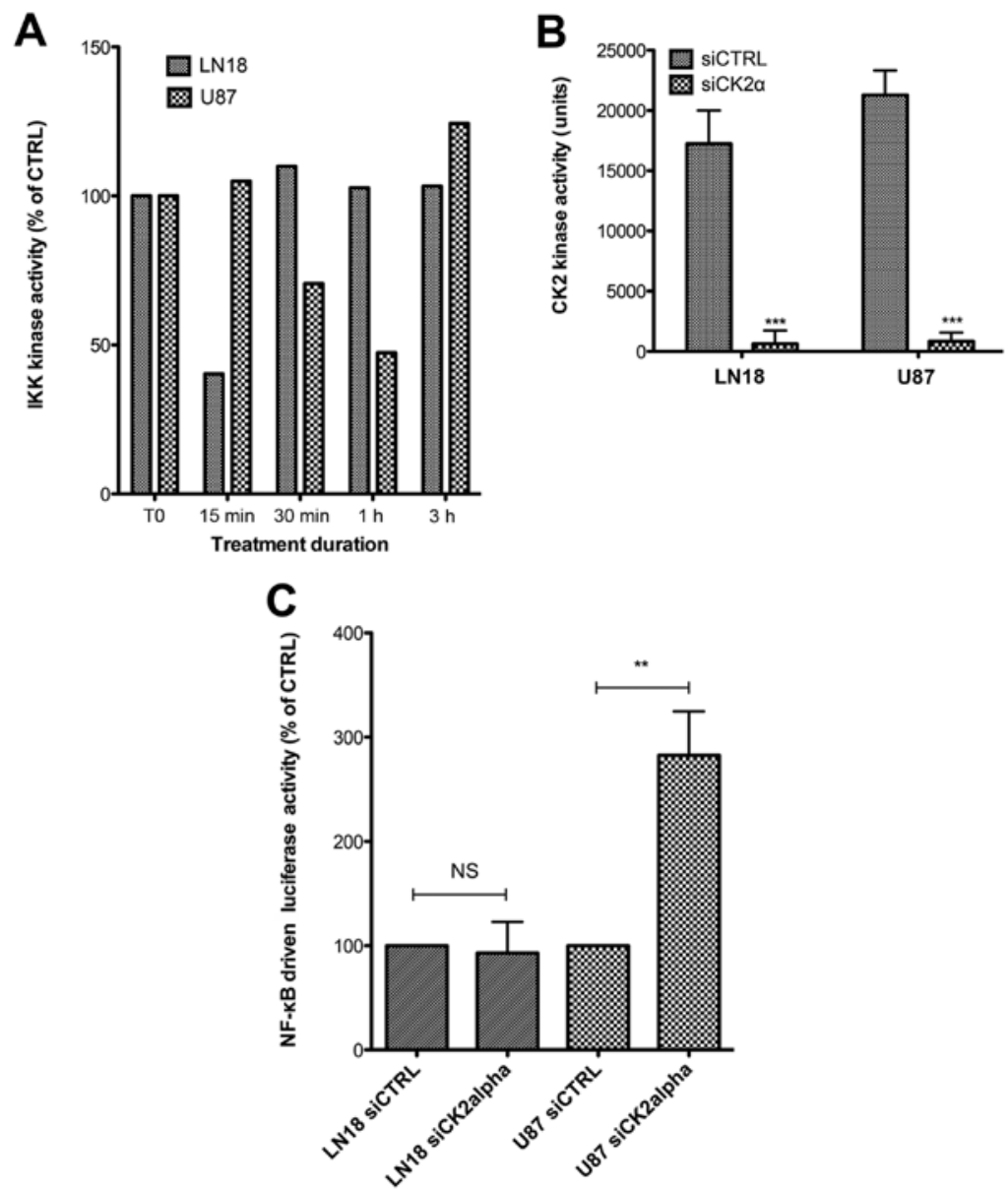

Figure 6. CK2 $\alpha$, IкB kinase, and delayed NF- $\mathrm{kB}$ response in GBM. (A) Transient inhibition of the IKK $\beta$ kinase activity following the inhibition of CK2 $\alpha$ with apigenin in LN18 and U87 cells (this experiment is representative of two independent experiments). (B) siRNA mediated inhibition of CK2 activity in LN18 and U87 cells. (C) NF-kB reporter gene activity $48 \mathrm{~h}$ after inhibition of CK2 activity with CK2 $\alpha$ siRNA. Statistics: (B) Two-way ANOVA; (A) Student's t-tests $\left({ }^{* *} \mathrm{P}<0.01,{ }^{* * * *} \mathrm{P}<0.001\right)$. 
A

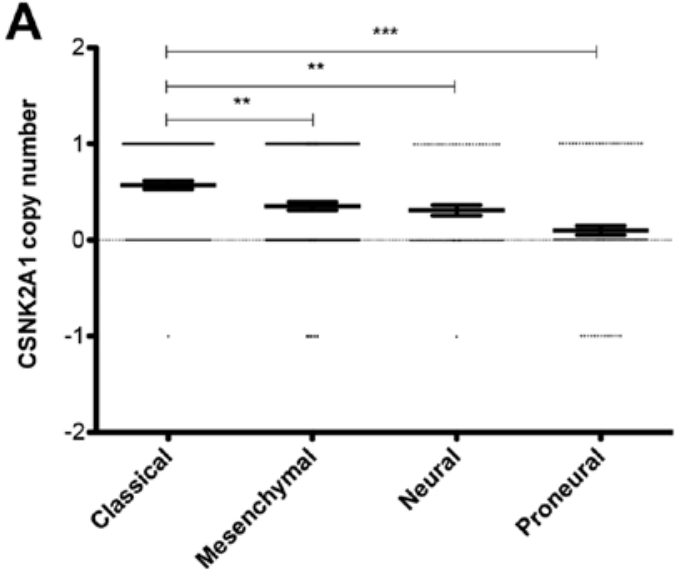

B

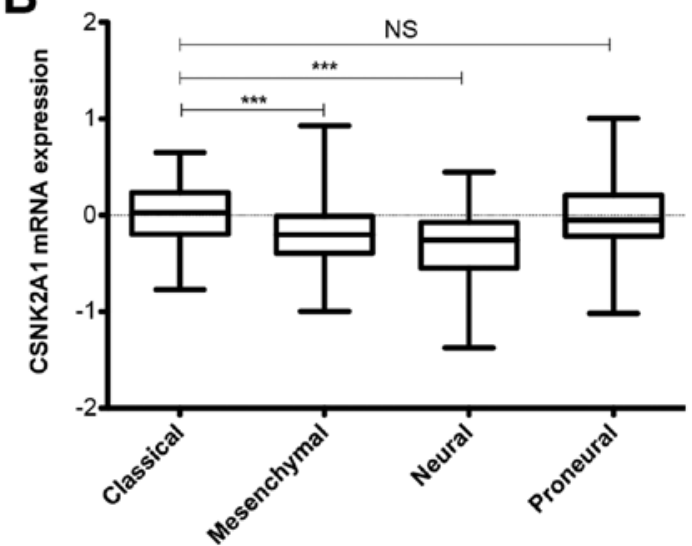

Figure 7. CSNK2A1 copy number and mRNA expression in 538 glioblastomas from the TCGA repository. (A) GISTIC-based CSNK2A1 CN estimates. (B) Agilent G450A2 microarray-based mRNA expression of CSNK2A1. Statistics: ANOVA with Tukey's multiple comparisons tests ( ${ }^{* *} \mathrm{P}<0.01$; $\left.{ }^{* * *} \mathrm{P}<0.001\right)$.

sensitivity of our cultures to CK2 inhibition with apigenin did not correlate with $\mathrm{CN}$ or mRNA expression of genes coding for ABC-family proteins 1 or 10 (data not shown). The toxicity of CK2 inhibition in glial tumors did not correlate with the CSNK2A1, A2 or B expression or CN (Fig. 6B). The oncogenic role of $\mathrm{CK} 2$ was also reported to depend on $\mathrm{p} 53$ function in some GBM cells (14). We however found that CK2 inhibition is toxic to both TP53 wild-type and mutant GBM cells, in agreement with previous findings in U251 cells (9). These results not only strike TP53 out as a potential predictive marker of efficacy for CK2-based GBM therapies, but also imply that additional mechanisms than p53 signaling are involved in the pro-survival function of this kinase.

Several pathways are known in this context to participate to the oncogenic properties of CK2 in gliomas. Among these, we showed previously that $\mathrm{NF}-\kappa \mathrm{B}$ is constitutively activated in malignant gliomas and prevents spontaneous apoptosis $(16,24)$. $\mathrm{CK} 2$ contributes to the hyperactivation of $\mathrm{NF}-\kappa \mathrm{B}$ in epithelial cancers by several pathways, notably via the activation the IKK complex and the proteasome-dependent degradation of $\mathrm{I} \kappa \mathrm{B} \alpha$ (25), and via the direct phosphorylation of $\mathrm{I} \kappa \mathrm{B} \alpha$, which targets it for degradation by calpains (11). We, however, showed here that calpains do not play any significant role in the constitutive activation of $\mathrm{NF}-\kappa \mathrm{B}$ in malignant gliomas, and that $\mathrm{CK} 2$ inhibition results in only a transient decrease of IKK- $\beta$ kinase activity and NF- $\kappa \mathrm{B}$ reporter activity in these tumors. CK2 activity thus likely plays only a minor role in the baseline NF- $\kappa \mathrm{B}$ activity in GBM cells $(11,25,26)$. Other pathways, such as the direct phosphorylation of caspase 3 (7) or the activation of STAT3 and 5 signaling $(5,9)$ are however known to show a more durable inhibition following CK2 knockdown and are thus more likely to explain the pro-survival effect of CK2 in gliomas. Interestingly, we observed that U87 malignant glioma cells, which are less sensitive to apigenin, Cx4945 and siCK $2 \alpha$ than the LN18 cells, present a delayed activation of $\mathrm{NF}-\kappa \mathrm{B}$ following $\mathrm{CK} 2$ inhibition, and that this activity might contribute to the therapeutic resistance of some gliomas to CK2 inhibition. Further studies are thus needed in order to confirm whether $\mathrm{NF}-\kappa \mathrm{B}$ activity induces resistance to CK2 inhibition and to evaluate the feasibility of a combined approach to target simultaneously these two pathways.
In conclusion, this study confirms the activation of CK $2 \alpha$ in malignant gliomas and indicates that $\mathrm{CK} 2$ is a potential therapeutic target in these tumors, irrespectively of the GBM subtype and TP53 status. A delayed NF- $\kappa$ B activation might however contribute to the therapeutic resistance of some malignant gliomas to $\mathrm{CK} 2$ inhibition, which paves the way to combined therapeutic strategies against these tumors.

\section{Acknowledgements}

This study was supported by Televie grants 7.4.564.11.F, 3.4.562.12.F, grant 7.247.330.12.F from the FNRS of Belgium, the Belgian National Cancer Plan grant no. 20-044 and the T\&P Bohnenn Fund for Neuro-Oncology research. We wish to thank Ms. C. Waltener for her expert help with the cell culture experiments, Dr Ch. Poulet for helping to classify the tumors according to Verhaak, and Dr V. Capraro for performing some of the kinase activity assays.

\section{References}

1. Stupp R, Taillibert S, Kanner AA, Kesari S, Steinberg DM, Toms SA, Taylor LP, Lieberman F, Silvani A, Fink KL, et al: Maintenance therapy with tumor-treating fields plus temozolomide vs temozolomide alone for glioblastoma: A randomized clinical trial. JAMA 314: 2535-2543, 2015.

2. Liu R, Wang X, Chen GY, Dalerba P, Gurney A, Hoey T, Sherlock G, Lewicki J, Shedden K and Clarke MF: The prognostic role of a gene signature from tumorigenic breast-cancer cells. N Engl J Med 356: 217-226, 2007.

3. Duncan JS and Litchfield DW: Too much of a good thing: The role of protein kinase $\mathrm{CK} 2$ in tumorigenesis and prospects for therapeutic inhibition of CK2. Biochim Biophys Acta 1784: 33-47, 2008.

4. Kroonen J, Artesi M, Capraro V, Nguyen-Khac MT, Willems M, Chakravarti A, Bours V and Robe PA: Casein kinase 2 inhibition modulates the DNA damage response but fails to radiosensitize malignant glioma cells. Int J Oncol 41: 776-782, 2012.

5. Mandal T, Bhowmik A, Chatterjee A, Chatterjee U, Chatterjee S and Ghosh MK: Reduced phosphorylation of Stat 3 at Ser-727 mediated by casein kinase 2 - protein phosphatase $2 \mathrm{~A}$ enhances Stat3 Tyr-705 induced tumorigenic potential of glioma cells. Cell Signal 26: 1725-1734, 2014.

6. Romieu-Mourez R , Landesman-Bollag E, Seldin DC, Traish AM, Mercurio F and Sonenshein GE: Roles of IKK kinases and CK2 in activation of NFKB in breast cancer. Cancer Res 61: 3810-3818, 2001. 
7. Turowec JP, Vilk G, Gabriel M and Litchfield DW: Characterizing the convergence of protein kinase CK2 and caspase-3 reveals isoform-specific phosphorylation of caspase-3 by CK2 $\alpha^{\prime}$ : Implications for pathological roles of CK2 in promoting cancer cell survival. Oncotarget 4: 560-571, 2013.

8. Nitta RT, Gholamin S, Feroze AH, Agarwal M, Cheshier SH, Mitra SS and Li G: Casein kinase $2 \alpha$ regulates glioblastoma brain tumor-initiating cell growth through the $\beta$-catenin pathway. Oncogene 34: 3688-3699, 2015.

9. Zheng Y, McFarland BC, Drygin D, Yu H, Bellis SL, Kim H Bredel $\mathrm{M}$ and Benveniste EN: Targeting protein kinase CK2 suppresses prosurvival signaling pathways and growth of glioblastoma. Clin Cancer Res 19: 6484-6494, 2013.

10. Verhaak RGW, Hoadley KA, Purdom E, Wang V, Qi Y, Wilkerson MD, Miller CR, Ding L, Golub T, Mesirov JP, et al; Cancer Genome Atlas Research Network: Integrated genomic analysis identifies clinically relevant subtypes of glioblastoma characterized by abnormalities in PDGFRA, IDH1, EGFR, and NF1. Cancer Cell 17: 98-110, 2010.

11. Romieu-Mourez R, Landesman-Bollag E, Seldin DC and Sonenshein GE: Protein kinase CK2 promotes aberrant activation of nuclear factor-kappaB, transformed phenotype, and survival of breast cancer cells. Cancer Res 62: 6770-6778, 2002.

12. Guerra B, Iwabuchi $\mathrm{K}$ and Issinger O-G: Protein kinase CK2 is required for the recruitment of 53BP1 to sites of DNA doublestrand break induced by radiomimetic drugs. Cancer Lett 345: 115-123, 2014

13. Olsen BB, Fritz $\mathrm{G}$ and Issinger $\mathrm{O}-\mathrm{G}$ : Characterization of ATM and DNA-PK wild-type and mutant cell lines upon DSB induction in the presence and absence of CK2 inhibitors. Int $\mathbf{J}$ Oncol 40: 592-598, 2012.

14. Dixit D, Sharma V, Ghosh S, Mehta VS and Sen E: Inhibition of Casein kinase-2 induces p53-dependent cell cycle arrest and sensitizes glioblastoma cells to tumor necrosis factor $(\mathrm{TNF} \alpha)$ induced apoptosis through SIRT1 inhibition. Cell Death Dis 3: e271, 2012.

15. Berendsen S, Varkila M, Kroonen J, Seute T, Snijders TJ, Kauw F, Spliet WG, Willems M, Poulet C, Broekman ML, et al Prognostic relevance of epilepsy at presentation in glioblastoma patients. Neuro Oncol: Sep 29, 2015 (Epub ahead of print]). doi: 10.1093/neuonc/nov238.

16. Robe PA, Bentires-Alj M, Bonif M, Rogister B, Deprez M, Haddada H, Khac MT, Jolois O, Erkmen K, Merville MP, et al: In vitro and in vivo activity of the nuclear factor-kappaB inhibitor sulfasalazine in human glioblastomas. Clin Cancer Res 10: 5595-5603, 2004.
17. Shen J, Channavajhala P, Seldin DC and Sonenshein GE: Phosphorylation by the protein kinase CK2 promotes calpainmediated degradation of IkappaBalpha. J Immunol 167: 4919-4925, 2001.

18. Robe PA, Nguyen-Khac M-T, Lambert F, Lechanteur C, Jolois O, Ernst-Gengoux P, Rogister B and Bours V: Sulfasalazine unveils a contact-independent HSV-TK/ganciclovir gene therapy bystander effect in malignant gliomas. Int J Oncol 30: 283-290, 2007.

19. Bredel M, Bredel C, Juric D, Duran GE, Yu RX, Harsh GR, Vogel H, Recht LD, Scheck AC and Sikic BI: Tumor necrosis factor-alpha-induced protein 3 as a putative regulator of nuclear factor-kappaB-mediated resistance to O6-alkylating agents in human glioblastomas. J Clin Oncol 24: 274-287, 2006.

20. Artesi M, Kroonen J, Bredel M, Nguyen-Khac M, Deprez M, Schoysman L, Poulet C, Chakravarti A, Kim H, Scholtens D, et al: Connexin 30 expression inhibits growth of human malignant gliomas but protects them against radiation therapy. Neuro-oncol 17: 392-406. 2015.

21. Robe PA, Rogister B, Merville M-P and Bours V: Growth regulation of astrocytes and C6 cells by TGFbeta1: Correlation with gap junctions. Neuroreport 11: 2837-2841, 2000.

22. Goffart N, Kroonen J and Rogister B: Glioblastoma-initiating cells: Relationship with neural stem cells and the micro-environment. Cancers (Basel) 5: 1049-1071, 2013.

23. Kore RA and Abraham EC: Inflammatory cytokines, interleukin-1 beta and tumor necrosis factor-alpha, upregulated in glioblastoma multiforme, raise the levels of CRYAB in exosomes secreted by U373 glioma cells. Biochem Biophys Res Commun 453: 326-331, 2014.

24. Bredel M, Scholtens DM, Yadav AK, Alvarez AA, Renfrow JJ, Chandler JP, Yu IL, Carro MS, Dai F, Tagge MJ, et al: NFKBIA deletion in glioblastomas. N Engl J Med 364: 627-637, 2011.

25. Yu M, Yeh J and Van Waes C: Protein kinase casein kinase 2 mediates inhibitor-kappaB kinase and aberrant nuclear factorkappaB activation by serum factor(s) in head and neck squamous carcinoma cells. Cancer Res 66: 6722-6731, 2006.

26. Guo S, Demicco EG, Romieu-Mourez R, Landesman-Bollag E, Seldin DC and Sonenshein GE: Inducible $\mathrm{I} \kappa \mathrm{B}$ kinase $/ \mathrm{I} \kappa \mathrm{B}$ kinase $\varepsilon$ expression is induced by CK 2 and promotes aberrant nuclear factor- $\kappa \mathrm{B}$ activation in breast cancer cells. Cancer Res 65: 11375-11383, 2005. 